\title{
QUEEN'S
UNIVERSITY
BELFAST
}

\section{Just what is narrative urgency?}

Simpson, P. (2014). Just what is narrative urgency? Language and Literature, 23(1), 3-22. https://doi.org/10.1177/0963947013510650

\section{Published in:}

Language and Literature

\section{Document Version:}

Peer reviewed version

\section{Queen's University Belfast - Research Portal:}

Link to publication record in Queen's University Belfast Research Portal

\section{Publisher rights}

(C) 2013 The Author

\section{General rights}

Copyright for the publications made accessible via the Queen's University Belfast Research Portal is retained by the author(s) and / or other copyright owners and it is a condition of accessing these publications that users recognise and abide by the legal requirements associated with these rights.

Take down policy

The Research Portal is Queen's institutional repository that provides access to Queen's research output. Every effort has been made to ensure that content in the Research Portal does not infringe any person's rights, or applicable UK laws. If you discover content in the Research Portal that you believe breaches copyright or violates any law, please contact openaccess@qub.ac.uk. 


\section{Language and Literature Narrative Special issue (Guest editor Marina Lambrou)}

Author name: Paul Simpson

Affiliation: Queens University, Belfast

Full postal address: School of English, Queens University, Belfast BT7 1NN, UK

Email address: p.simpson@qub.ac.uk

Telephone/Fax (where possible):

\section{Just what is narrative urgency?}

Abstract: (around 250 words)

This paper takes as its main point of departure a body of empirical research on reading and text processing, and makes particular reference to the type of experiments conducted in Egidi and Gerrig (2006) and Rapp and Gerrig (2006). Broadly put, these experiments (i) explore the psychology of readers' preferences for narrative outcomes, (ii) examine the way readers react to characters' goals and actions, and (iii) investigate how readers tend to identify with characters' goals the more 'urgently' those goals are narrated.

The present paper signals how stylistics can productively enrich such experimental work. Stylistics, it is argued, is well equipped to deal with subtle and nuanced variations in textual patterns without losing sight of the broader cognitive and discoursal positioning of readers in relation to these patterns. Making particular reference to what might constitute narrative 'urgency', the article develops a model which amalgamates different strands of contemporary research in narrative stylistics. This model advances and elaborates three key components: a Stylistic Profile, a Burlesque Block and a Kuleshov Monitor. Developing analyses of, and informal informant tests on, examples of both fiction and film, the paper calls for a more 
rounded and sophisticated understanding of style in empirical research on subjects' responses to patterns in narrative.

\section{Keywords}

burlesque (in style); film narrative; Kuleshov (effect); narrative style; Pyscho; text processing; 'urgency'

\section{Acknowledgements}

In addition to the anonymous reviewers at Language and Literature, I am grateful to the following colleagues and research students for their helpful comments on this article at various stages of its development: Mick Short, Zoe McCaw, Helen Morrow, Willie van Peer, Geoff Hall and Marina Lambrou. I am also grateful to Ashley Holmes for her artwork, to Stephen Mullan for his assistance with film editing and to Eileen Morgan for her help with the statistical analyses in this article. I would like to thank the undergraduates at Queen's University Belfast who took part in the formal informant-based experiment. Finally, for their insightful comments and for participating informally in some of the practical activities developed in this article, I would like to thank delegates who attended the following conferences in 2012: the joint Poetics and Linguistics Association - Société de Stylistique Anglaise conference at Huddersfield University, UK; the Chinese Stylistics Association conference at the University of Soochow, Jiangsu Province, China. 


\section{Introduction}

The present study probes different aspects of narrative organisation using a range of models in contemporary stylistics. It draws its principal impetus from a body of work in experimental cognitive psychology that uses empirical testing methods to explore the processes underlying reading and text processing. In the wake of its so-called 'cognitive turn', it is perhaps no surprise that stylistics continues to assimilate significant studies by psychologists on textual processing and interpretation such as that embodied by, for example, Gerrig (1993), Gibbs (1994) or Oatley (2003). However, the particular body of psychological research drawn upon here is a series of journal publications which all, to some degree, investigate how readers experience and react to different stories or to different versions of the same story (Egidi and Gerrig 2006; Gerrig and Rapp 2004; Rapp and Gerrig 2006). A short overview of these studies follows, and thereafter the remainder of this section narrows in focus to consider one particular narrative mechanism which features in this collection of work. The subsequent sections of the present article will then attempt to illustrate what stylistics, in broader terms, can contribute to research on narrative processing, and more narrowly, how a framework of analysis built from the palpable stylistic techniques of film and prose narratives can enrich, re-define or even challenge the empirical approaches charted in this section.

The experimental methods used across the relevant psychological work are mainly judgement tasks and reading time tests. These methods, which are underpinned by quantified data and statistical analysis, are used to probe both readers' predictions about, and readers' predilections for, particular kinds of narrative 
outcome. A key research question, for instance, concerns the processes by which readers attend to the match between characters' actions and characters' goals, and on this question, Egidi and Gerrig report that participants in the reading time experiments tend to show sensitivity to any mismatches between the two (2006: 1322). Similarly, readers appear to be more comfortable with (i.e. take less time to read) a narrative outcome that is established in a prior 'biasing context' (Egidi and Gerrig 2006 passim). Straddling again the ideas of reader prediction and reader predilection, Rapp and Gerrig argue that without any special prompting from the text, readers are likely to prefer that characters succeed rather than fail (2006: 55). Moreover, they suggest that the reader's alignment with the character's desired outcome can supplant the reader's understanding of a moral outcome, on the grounds that the moment-bymoment experience of an ongoing narrative is enough to override the 'good guy / bad guy’ schema (Rapp and Gerrig 2006: 65).

Drilling down further into these studies reveals a topic which in itself poses an intriguing challenge for stylistic inquiry. In their study of the way reading times are influenced by characters' goals in a story, Egidi and Gerrig (2006: passim) argue that readers generally tend to identify with characters' goals the more 'urgently' those goals are narrated. More specifically, they point out that readers are 'responsive to the match between the urgency of characters' goals and the means characters take to achieve those goals' (Egidi and Gerrig 2006: 1323). Elsewhere, they talk of 'urgent motivation' (1326), of 'mild and urgent goals' (1325) and of goals of 'moderate or urgent importance' (1326). However, these observations beg one key question: just what exactly is narrative 'urgency'? Moreover, how can different degrees and intensities of urgency (pace the comments of Egidi and Gerrig) be delivered and detected in a story. 
Crucially, the texts upon which such reading experiments are conducted are normally written by the researchers themselves, and the Egidi and Gerrig study is no exception in this regard. From a stylistic perspective, the risk in working exclusively with short passages that have been self-penned is that it makes it difficult to present objectively verifiable linguistic criteria. Because the textual material has been designed entirely to suit the purposes of the experiment, the core linguistic variables have therefore to be taken entirely on trust. For example, one reading experiment in the relevant set of publications involves two variants of a story about a character, Nell, whose goal is to leave the building which houses her office (Egidi and Gerrig 2006: 1322-3). One variant is purportedly more urgently narrated than the other, although somewhat disquietingly, the authors then analyse their own stories as if they were independently created narratives taken, as it were, from the real world. In respect of the urgent version, it is claimed that 'Nell's dramatic behaviour suggests that she has an urgent reason for her goal' while in the less urgent version 'Nell's ordinary actions suggest that she has a more mundane motivation' (1323).

It is certainly not the intention of the present study to be critical of this body of work. Indeed, the robustness of other aspects of the psychological research, such as the quantitative experimentation and the compelling statistical analyses, far outstrips what can be achieved in the present article. There are moreover notable benefits concerning controllability (and by imputation, falsifiability) in using manipulated data in a laboratory setting. Rather, the aim of this study, from here onwards, will be to enrich the experimental approach by grounding some of its underpinning concepts which are, after all, founded on patterns of language and style — in a more robustly conceived definition of narrative structure. 


\section{Narrative urgency: a stylistic perspective}

The foregoing discussion has intimated that stylistics is, and should be, well equipped to deal with subtle and nuanced variations in textual design. Indeed, if it is to have any explanatory potential at all, stylistics must ab initio be capable of locating frameworks of interpretation in specific patterns in text. The writer's craft is, to state the obvious, the very nuts and bolts of stylistic description. So with respect to the particular stylistic feature scrutinized in this paper, a novelist or creative writer might legitimately question a stylistician thus: 'How do I make my story feel urgent?' or 'What do I need to do with my writing style to signal a sense of narrative urgency?'. For that matter, inverse questions might reasonably be posed: 'What do I need to do with my language to take away suspense?', 'How can I signal relaxation or nonurgency?' and so on.

The overview that follows is in some respects a response to the questions of our would-be novelist or story-teller. Six core features are proposed, ranging across different layers in stylistic organisation. If not quite couched in the lay terms reasonably demanded by a creative writer, the features are presented nonetheless in an axiomatic and programmatic way. Collectively, they make for an initial stylistic profile (SP) for delivering 'urgency' in narrative composition.

\section{The Stylistic Profile (SP)}

Taking into consideration aspects of the co-text, techniques in foregrounding and different methods of narrative delivery, the profile elaborated here moves from patterns in the lexico-grammar, through the semantic metafunctions, towards more cognitively-driven models of narrative understanding. Illustrations will follow later, but the first, and most intuitively obvious, grammatical feature of the SP involves the 
use of simple sentences that comprise a single clause. That is to say, the 'onset' of urgency is signalled by a compositional shift to one-clause structures that are normally presented either as stand-alone orthographic sentences or as clusters in asyndetic coordination. These clauses may be, or may comprise, moodless 'minor' units. If the clauses are co-ordinated syndetically, then the pattern will be paratactic, not hypotactic, and will be chained with additive, adversative and temporal conjuncts. This organisation of the textual metafunction stands in contrast to more sophisticated patterns of elaboration and enhancement (Halliday and Matthiessen 2004: 410-3) that employ conditional, substractive, concessive, replacive or other types of conjunctive adjuncts.

Moving from the textual metafunction to the experiential, the transitivity profile needed for 'urgency' is one that embodies the world of physical actions and events, less so the world of consciousness, and less so again the world of abstract relations. This translates into a predominance of 'doing' style clauses, relayed principally through Material and Behavioural processes. These take precedence over Mental processes, which render inner states of cognition and perception, while more remote again are Relational processes which present the most 'static' relationships of being. Importantly, the transitivity profile also permits Material processes that have been negated. This is because the negation often presupposes that the process, although it is not brought about, was at least attempted (see Simpson and Canning forthcoming). Indeed, the 'disnarrated' event (Prince 1988) often becomes more salient precisely because it reports a failed, perhaps desperate, attempt to bring about a required course of action in the story. Lastly, Verbalisation processes - processes of 'saying' - tend to be affected by a higher-order stricture governing their realisation in the narrative. In other words, while the portrayal of speech can be very much a feature 
of narrative urgency, it is the particular mode of representation for Speech (or sometimes 'verbalised' Thought) that has most bearing on the make-up of the SP. This issue will be returned to shortly.

The third category of the SP is informed by particular patterns around the interpersonal metafunction. Overall, the broad orientation in the profile is towards categorical expression at the expense of what stylisticians, from Roger Fowler onwards, have referred to collectively as 'evaluative modalities' (Fowler 1986: 132). In other words, if a shift towards narrative urgency takes place within a story, there will be a concomitant shift away from the use of modal operators. In particular, the SP requires a stripping away of the epistemic markers that indicate, and comment on, matters of belief, knowledge and opinion. This strategy is perhaps obvious given the slowing down effect engendered when a narrator or character pauses to reflect on the epistemological nature of the world around them. However, there may be a case, as we shall see later, for retaining in the SP some aspects of the other modal systems. Deontic modality, when orientated to expressions of 'obligation' and 'necessity', can play an important part in precipitating and sustaining narrative urgency because it helps relay the intensity particular to a narrative action or outcome.

A fourth and no less crucial aspect of the SP concerns the time frame of the narrated action. Following Genette's terms in structuralist narratology, the broad concept of duration captures the overall temporal sweep of a story, with the term scene signalling that the story's time-line is isochronous with its narrating time (Genette 1980: 86ff). Put more simply, scene is when the time taken to tell the story is the same as the time the story itself takes. By contrast, non-isochronous narrative duration includes pausing, where zero time passes, or acceleration, where the action of the story outstrips narrative delivery time. An important characteristic of the SP, 
narrative scene tends to relay only the core action and, in its rendering of dialogue in particular, often feels very much like a screenplay (Simpson and Hardy 2008: 129).

Particular patterns in the representation of dialogue and, more generally, in forms of speech and thought presentation, contribute a fifth feature to the SP. This criterion for narrative urgency postulates that, if present, speech or thought will be rendered in free forms, either as Free Direct Discourse or Free Indirect Discourse. Most importantly, and echoing the point made above about narrative scene, the removal of reporting clauses, which is the defining characteristic of the Free mode, blocks the possibility for any narrative commentary on the delivery of the speech or thought act. Moreover, the reported material itself will often be grammatically sparse or elliptical. The Free Direct mode, in particular, lends itself to the presentation of simple polar interrogatives, moodless structures or non-indicative forms like imperatives.

The sixth feature of the SP is to do with its location in the narrative hierarchy. The tenets of Text World Theory (Werth 1999; Gavins 2007) help situate the SP in the cognitive domains of discourse-world, text-world and sub-world(s). It is suggested here that for narrative urgency to be sustained, the story should be maintained in the primary text-world and not in a sub-world. In other words, actions and events need to be anchored in the deictically-proximal cognitive reference point that is the main story, and not in, for example, a negated or counterfactual sub-world that is accessible only to one of the 'enactors' in the text world. This criterion of the SP ties in with the observations on modality above.

The SP, as conceived in the foregoing outline, is more a constellation of stylistic tendencies than a rigid checklist for which every feature needs to be realised. 
Undoubtedly, more features could be added, and some of the features presented thus far could be contested or modified. That said, it is important now to illustrate the explanatory power of the SP by applying it to some narrative writing that makes a good case for being described as 'urgent'. The following extract is from Ian McEwan's novel Atonement. Robbie Turner and his fellow soldiers, part of the British Expeditionary Force of 1940, are on the long retreat to the beaches at Dunkirk. Their column, which also includes French citizens, is attacked suddenly by the Luftwaffe:

The boy had gone silent with shock. His mother wouldn't stand. Turner pointed to the Stuka coming in over the rooftops. They were right in its path and there was no time for argument. She wouldn't move. He threw himself down into the furrow. The thuds of machine-gun fire in the ploughed earth and the engine roar flashed past them. A wounded soldier was screaming. Turner was on his feet. But the woman would not take his hand. [. . .] Turner took a step back. Then he ran.

(McEwan 2001: 237)

The postulates of the SP are very much in evidence here. The core grammatical indices - short single clause sentences - resonate throughout the passage. A moodless unit forms the first part of the sentence beginning 'The rippling thuds of machine-gun fire in the ploughed earth ...' while the few conjunctions that are present are 'and', '[b]ut', and '[t]hen' which are, respectively, additive, adversative and temporal connectors. Material processes ('He threw himself down into the furrow') and Behavioural processes ('A wounded soldier was screaming') are at the fore, alongside negated Material processes (e.g. 'His mother wouldn't stand') which report failed attempts to implement the requisite strategies for survival. Overall, categorical expression dominates in a passage devoid of any evaluative modality, the upshot of which is that the passage's time-line becomes isochronous with its narrating time. This brings about narrative scene because each event unfolds in line with the time taken to tell it. Finally, the narrative events are fixed squarely within the primary text 
world without any projections, via perhaps its central character Robbie Turner, into other, more remote, sub-worlds (although see below).

Although there is no speech or thought presentation in the extract presented, as the Stuka attack progresses there appear elsewhere sudden intrusions of short fragments of reported speech. Free modes, where the reporting clauses have been stripped away, tend to dominate such that the intrusions become unattributed, disembodied commands whose speaking sources are lost amid the melee of the attack. Variants include stripped-down imperatives like 'Disperse!' and 'Take cover!' alongside exhortative declaratives presented in the Free Direct mode, such as 'We've got to run again. We're too close to the road.' (McEwan 2001: 235-6). Fulfilling, again, the conditions of the SP, there are moodless or ellipted interrogatives ('Which way?', 238) or occasionally, interrogatives rendered in Free Indirect Speech, such as 'Was it the all clear?' (238).

An important trait of the SP is that it is inherently contrastive: narrative urgency works most effectively in opposition to the 'non-urgent' events and episodes around it. In respect of this, it is worth noting that McEwan's description of the Stuka attack is not stylistically uniform or monochrome. For instance, in one quiet moment of reflection, at the very height of the strafing, Robbie Turner imagines the safety afforded by nearby trees:

But the woods were near, there would be streams and waterfalls and lakes in there. He imagined a paradise.

(McEwan 2001: 238)

This little oasis of stylistic calm is a wholesale departure from the postulates of the SP. Observe in these intratextually foregrounded sentences the Relational and Mental processes and the striking intra-clausal co-ordination ('streams and waterfalls and 
lakes'), all of which serve to slow the narrative pace markedly. Notice also the hypothetical modal 'would' and the counterfactive predicator 'imagined' which, through the thoughts of Robbie, engender a world shift away from the primary text world and into an 'enactor-accessible' epistemic sub-world (see Gavins 2007: 114). The deictic signature 'in there' consolidates this projection. Given the co-text in which it is framed, this arresting sequence is as powerful as the sparer, more acetic prose that surrounds it.

This contrastive dimension of the SP is important. In a kind of Boyle's law of stylistics where for every action, there is an equal and opposite reaction, the criteria for non-urgent narration sit in a binary opposition to those framed by the SP. In other words, 'non-urgent' narration will by imputation require the very presence of evaluative modalities, subordinate conjunctions, hypotactic coordination, enactor accessible sub-worlds, narrative pauses and stretches, transitivity processes expressing abstract relations, and so on. Although this is moving a little beyond the scope of this article, it is worth referencing briefly a prima facie case for what might be classified as 'non-urgent' narration. The depiction of the key murder scene in Joseph Conrad's The Secret Agent (Conrad 2011: 212-3; and see the stylistic analysis in Kennedy 1982) is about as far removed from the tenets of the SP as can be imagined. Admittedly, Conrad's repetition of the adjective 'leisurely' throughout this episode is perhaps a rather unsophisticated clue about his intended framework of narrative transmission. Nevertheless, Mr Verloc's inertia as his wife approaches with a knife makes for an excellent point of comparison with the constraints of the SP. For instance, the passage is peppered with Mental processes of perception, reaction and cognition, where Verloc conceives, inter alia, an elaborate 'plan of defence'. These forays into imagined worlds are extended grammatically over ever-lengthier projected 
and embedded clauses, and to such an extent that the stabbing is over by the time the narrative returns to it: 'The knife was already planted in his breast [my emphasis]'. The markedly non-isochronous relationship between story event time and story telling time is further stretched by the use in the text of 'universal truths'. Expressing socalled authorial modality, these timeless present tense structures (e.g. 'Hazard has such accuracies') create narrative pauses where zero time passes. Overall, these and other aspects of Conrad's stylistic technique, when consolidated, frame a kind of 'anti-SP' model of narrative transmission.

The six key features of Stylistic Profile, as sketched, are admittedly programmatic but they are intended to mark the beginning of where stylistics might intersect in useful ways with the experimental work in psychology adumbrated earlier in the paper. However, before exploring this further through a more empiricallydriven analysis of data, some 'checks and balances' need to be made to the SP to create a more nuanced framework of analysis. These modifications are the focus of the next section.

\section{Narrative urgency: checks and balances}

This short section makes some adjustments and modifications to the SP by probing two particular issues. The first issue, addressed shortly, raises an old fashioned dichotomy which concerns the relationship between style and content. The degree of 'fit' between style and content, it is argued, can serve as a check and counterbalance to the interpretative mechanisms of the SP in narrative discourse. The second issue, addressed later, concerns the presence or otherwise of certain types of character in different levels of the story. The presence of one particular type of embedded 
character-narrator, it is suggested, offers an important supplement to the SP model advanced thus far.

In very informal terms, the technique of 'high burlesque' works by elevating, through a grandiose or inflated style, some trivial or inconsequential content or subject matter (Nash 1985: 85-6). By contrast, low burlesque, or 'travesty', uses an undignified style in addressing lofty or serious subject matter. No claim is made here for discovering any new kind of stylistic trope: burlesque, if rather loosely conceived, has been around since the Comedia dell'Arte of sixteenth century Italy, later becoming the stylistic mainstay of the eighteenth century 'mock heroic' poetic technique of, for example, Alexander Pope. Without straying into a full-blown essay in linguistic humorology, the relevance of the concept of 'high burlesque' to the present discussion is that the mismatch in style that it engenders often, and obviously, comically undercuts the story events portrayed. Moreover, the perception of an incongruity in style is often enough to de-stabilise the assumed sincerity condition attached to the utterance (Simpson 2003 passim), and that, in turn, facilitates and enables humorous tropes such as the spoof, the pastiche, or the parody. The problem for the SP, as conceived thus far, is that it is simply not sensitive to such ironicallyframed forms of comic discourse. This limiting condition to the SP framework will be referred to as the Burlesque Block (BB).

By way of brief illustration, consider the following extract from Jerome K. Jerome's novel Three Men in a Boat. The novel's first person narrator has just been perusing a medical encyclopaedia only to convince himself that he suffers from all but two of the numerous ailments listed therein:

I tried to examine myself. I felt my pulse. I could not at first feel any pulse at all. Then, all of a sudden, it seemed to start off. I pulled out 
my watch and timed it. I made it a hundred and forty-seven to the minute. I tried to feel my heart. I could not feel my heart. It had stopped beating.

(Jerome 1986: 5)

All the hallmarks of the SP are in evidence here, but in spite of the frenetic and fastpaced feel to the passage, the mock heroic framework delivers not urgency but a melodramatic 'fake' tension. Indeed, the very portentousness of the narrative delivery works in ironic counterpoint to the triviality of the hypochondriac narrator's selfabsorption, as he convinces himself that the only ailments he is not afflicted by are tennis elbow and housemaid's knee. The collision between subject matter and style of delivery is of itself sufficient to make for pastiche. Very different from the McEwan passage, the sense of 'urgency' in this passage, with its style-content mismatch and attendant pragmatic condition of insincerity, is heavily mitigated by the Burlesque Block.

The discussion in the earlier part of this article probed the intersection of characters' goals, preferred outcomes and moral outcomes. In the context of narrative urgency in particular, it is argued here that these dimensions of narrative processing need to be ratified and consolidated by a particular type of character in the story, a character who occupies a position of focal prominence. Useful concepts in stylistics which come close to capturing this idea are focaliser, enactor, reflector of fiction, centre of consciousness and so on, but for the present purposes, terminology will be borrowed from film theory. Set out below, this supplementary condition to the SP will be referred to as the Kuleshov Monitor (KM). 
In 1917, the Russian film director Lev Kuleshov developed an experiment that explored audience reactions to a sequence of specially edited footage (Levaco 1974; Russell 2005; Pramaggiore and Wallis 2005: 162). Kuleshov's contention was that a sequence of two shots would transcend significantly the individual information contained within each shot, and that, moreover, audiences would search out significances in meaning that were not necessarily warranted. Intercut with the same shot of actor Ivan Mozhukhin's expressionless face were three different images: an abandoned bowl of soup, a woman's corpse in a coffin and a young girl with a teddy bear. Kuleshov claimed that the audience attributed different emotional responses to the actor, with his expression (interpreted as) registering, respectively, pensiveness at the forgotten soup, sorrow at the woman's demise and a tender smile at the little girl. The audience even compliments Mozhukhin on his skill as an actor. As Ross argues (2012: 381), the experiment demonstrated to filmmakers the benefit of giving closeups determined and unambiguous meaning through association with their prior and subsequent shots. The significance of this was not lost on director Alfred Hitchcock who offers his own less grisly, if rather more salacious, variant on the Kuleshov experiment (Hitchcock 2013). Not only does this makes for an important connection to the design of the experiment in the following section, but the Kuleshov effect offers a chance for a kind 'semantic induction' (Willemen 1981: 63) by viewers and, by imputation, readers. The Kuleshov Monitor (KM) is therefore defined here as a character-narrator who is on the same plane of exegesis as the story. The KM complements the SP through the way in which it offers a Mozhukhin-style anchor to the ongoing flow of a story, providing a peg upon which reader and viewer emotion can be 'hung'. Importantly, the KM does not require any explicit or elaborate 'emotional' display, such as that typically associated with a Jamesian 'centre of 
consciousness' in fiction. Indeed, such effusiveness in discourse presentation - as observed above - runs in any case counter to the idea of urgency. In sum, the presence of a KM within a set of contiguous narrative events is sufficient to form a reference point which allows for an intricately interwoven pattern of reader and viewer interaction. The following section will attempt to illustrate these claims.

\section{Narrative (and) processing revisited}

This section probes further the issues raised above, by exploring the outcomes of a simple experiment in narrative processing. The experiment involves charting different groups' reactions to a key scene in Alfred Hitchcock's film Psycho (1960). The design, implementation and outcomes of the experiment are documented further below, but some prior contextualisation of the extract chosen is in order here. In this episode, Norman Bates (played by Anthony Perkins) disposes of Marion Crane (Janet Leigh), the murdered visitor to his hotel, whose body is in the boot of the car that Bates attempts to submerge in a nearby swamp. Whereas Bates is ultimately revealed in the denouement as the eponymous 'psycho' — the killer driven by the overbearing persona of his late mother - all viewers will know at this stage in the film that he is, at least, a co-conspirator in Marion's murder. The scene is played out in the following sequence of shots (and accompanying plates). As there is no dialogue or musical soundtrack to capture, and only mise-en-scène 'noise' such as the car door closing or the gurgle of the swamp as the car sinks, the 'multimodal' representation of the scene proves to be relatively straightforward.

'The Car in the Swamp Scene', Chapter 12, Psycho, 2:45 minutes. 
1: A night time establishing shot of the rear of Marion's car with its number plate clearly visible.

2: $\quad$ The shadowy figure of Bates emerges from the driver's (left) side and pushes the car towards the marsh.

3: $\quad$ A series of four rapid $180^{\circ}$ cuts, back and forth, between the view of the progressively sinking car and medium close-ups of Bates, chewing nervously, as he watches its progress.

4: $\quad$ A $180^{\circ}$ cut back to the rear of the car, which suddenly stops sinking with the trunk of the car left in view (see Plate 1).

5: $\quad$ Another close-up of Bates, who registers the stalled sinking. He twitches, stops chewing, and looks furtively to his right, then behind, and then back around to his left (see Plate 2).

6: $\quad$ A return to the shot of the partially submerged car which now begins to sink again, finally disappearing from sight.

7: Just after the car finally disappears into the swamp, the final shot of the scene: a close-up of Bates, who, with a self-satisfied grin, begins to chew again (see Plate 3).

[insert the 3 plates around here]

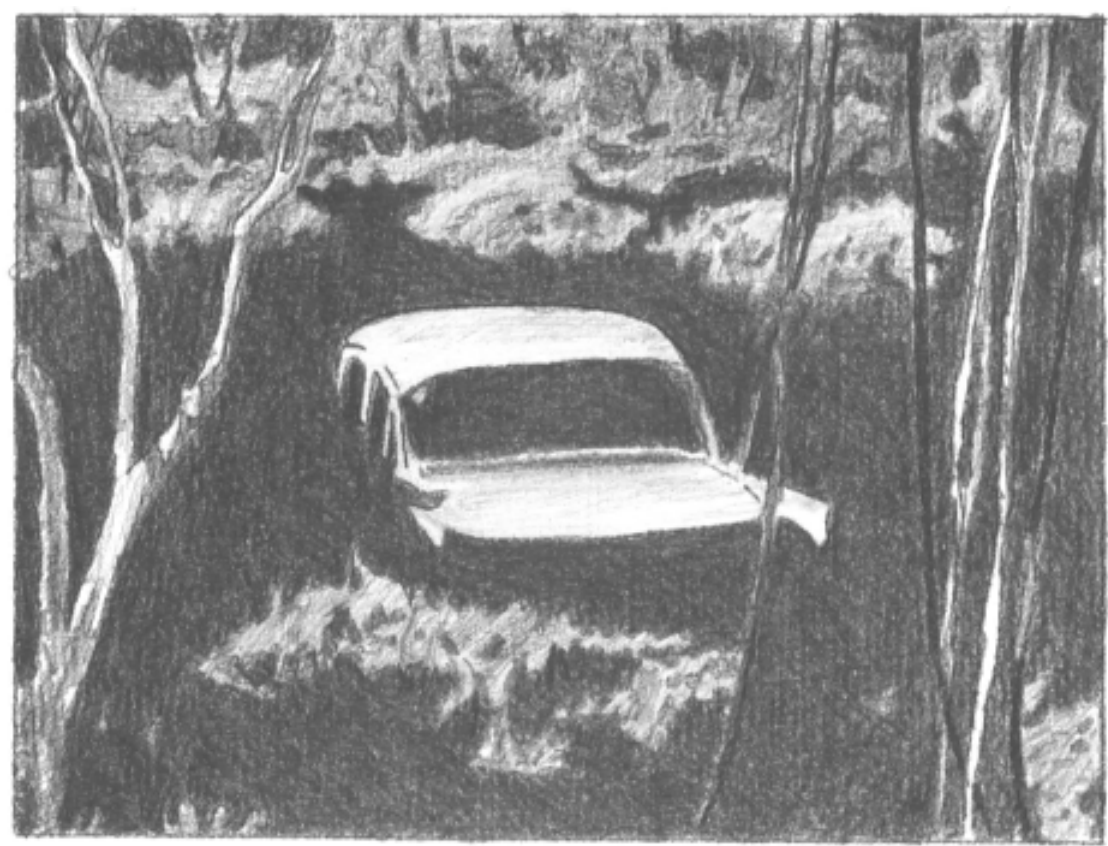

Plate 1 


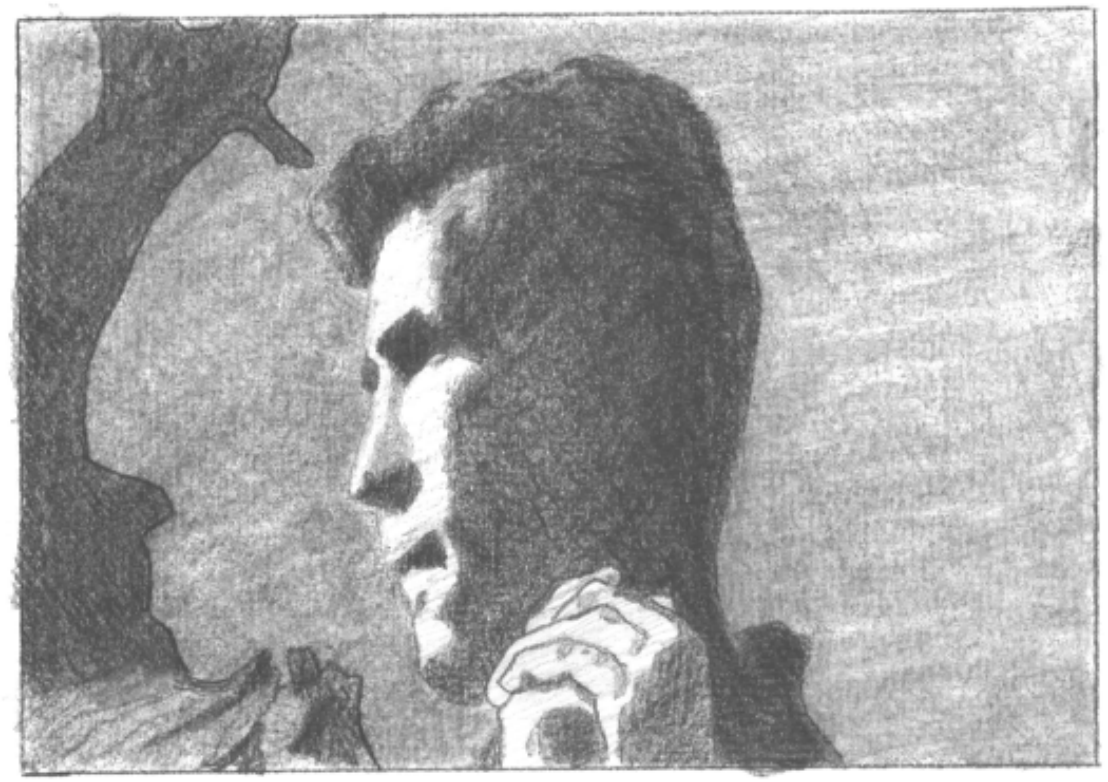

Plate 2

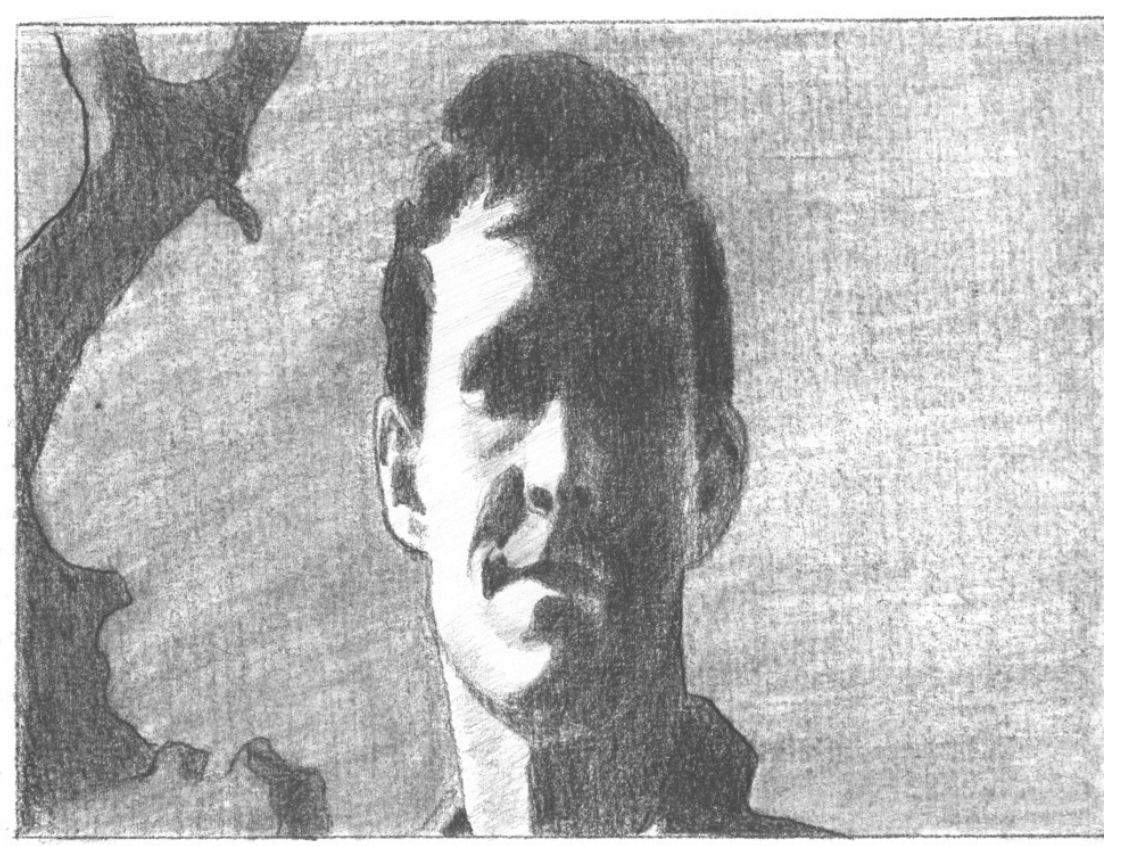

Plate 3

I have intimated elsewhere that this episode offers excellent material for exploring a variety of cross-sections between style, cognitive affect and narrative processing (Simpson 2010). For instance, viewers' reactions to the scene raise some intriguing issues, not least because there seems to be a desire to see Marion's car sink into the 
swamp. Admittedly, this impression was garnered, in the earlier study, from nothing more than a show of hands in response to a screening of the episode to a large lecture audience (2010: 308). While this suggests, pace the themes explored earlier, that the desired outcome of the character might well supplant the moral framework of the viewer, the experiment, such as it was, neither positions that reaction in an empirically informed framework nor locates it in a focussed description of narrative style. One might ask a number of contingent questions. For instance, to what extent is Hitchcock's focalisation strategy for Bates, through the eye-line match and the significant cuts back and forth, a factor in interpretation? And what would the audience reaction have been were Bates's perceptual involvement diluted? In other words, what if the same scene were played out without the mirroring and registering effect of the Kuleshov Monitor?

Addressing these questions, an experiment was designed which, like those of Gerrig and his co-researchers, drew on reactions to different forms of the same text by undergraduate students. In this instance, informants were asked to respond to a manipulated version of the swamp scene that had the close-ups of Bates in event 3 and all of event 5 removed. In other words, while the pause in the sinking was retained, the reaction to it, through the cuts to Bates's non-verbal behaviour, was edited out. It is of course essential in comparative analyses of this sort to equate for length the material used (Rapp and Gerrig 2006: 57). Interestingly, and intersecting with the earlier discussion on narrative scene, the editing process for length calibration revealed how Hitchcock shot the scene in real time, with each cut back from Bates showing the car a little more submerged than it was before. Therefore, in the editing process, slow dissolves were inserted to link together as seamlessly as 
possible the stages in the sinking of the car. This ensured that the manipulated sequence was the same length as the original.

Two groups of forty undergraduate students participated in the experiment. Both groups, A and B, were students at Queen's University Belfast, taking English either as a Single subject or as part of a Joint pathway involving History, Politics, Linguistics or Drama. All participants were from Great Britain or Ireland, bar eight of the cohort who were visiting students from continental Europe. Group A was shown the original, unadulterated clip; group B the manipulated version. A questionnaire was provided (see Appendix 1) which offered some context to the film, or at least, as much context as anyone watching the film for the first time would have at this juncture in the story. Importantly, the questionnaire asks for five responses, the first four of which (e.g. asking for the name of the actor or the number plate of the car) are 'placebo' style questions. This guaranteed that the pertinent question, probing implicitly participants' experience of narrative urgency, was relegated to fifth and last on the questionnaire: 'On a scale of $1-10$, how much did you want the car to sink? [. . .]'. The use of the numerical scale on this question contributed further to the mixed style of response elicited on the questionnaire as a whole, which required underlining, numbering and full text answers.

At one extreme, an overall score of 40 on question five would signal maximal concurrence where every group member felt very strongly that they did not want the car to sink. A collective score of 400 would signal the opposite, with every participant feeling strongly that they did want the car to sink. A median score of 200 would indicate that participants were generally indifferent to the progress of the car; that they were 'not bothered', to adopt the terms of the questionnaire. The actual 
results are revealing. The following Tables show, respectively, calibrated scores, raw averages, and breakdowns by bar chart of the collected responses to question five:

\begin{tabular}{|l|l|l|l|l|l|l|l|l|l|l|}
\hline Group A & 1 & 2 & 3 & 4 & 5 & 6 & 7 & 8 & 9 & 10 \\
\hline & 0 & 0 & 0 & 2 & 5 & 5 & 10 & 12 & 3 & 3 \\
\hline
\end{tabular}

\begin{tabular}{|l|l|l|l|l|l|l|l|l|l|l|}
\hline Group B & 1 & 2 & 3 & 4 & 5 & 6 & 7 & 8 & 9 & 10 \\
\hline & 6 & 3 & 6 & 0 & 17 & 3 & 4 & 1 & 0 & 0 \\
\hline
\end{tabular}

Table 1: Calibrated scores for question five

\begin{tabular}{|l|l|l|}
\hline GROUP & TOTAL SCORE & RAW AVERAGES \\
\hline A & 286 & 7.15 \\
\hline B & 169 & 4.23 \\
\hline
\end{tabular}

Table 2: Averages for question five 


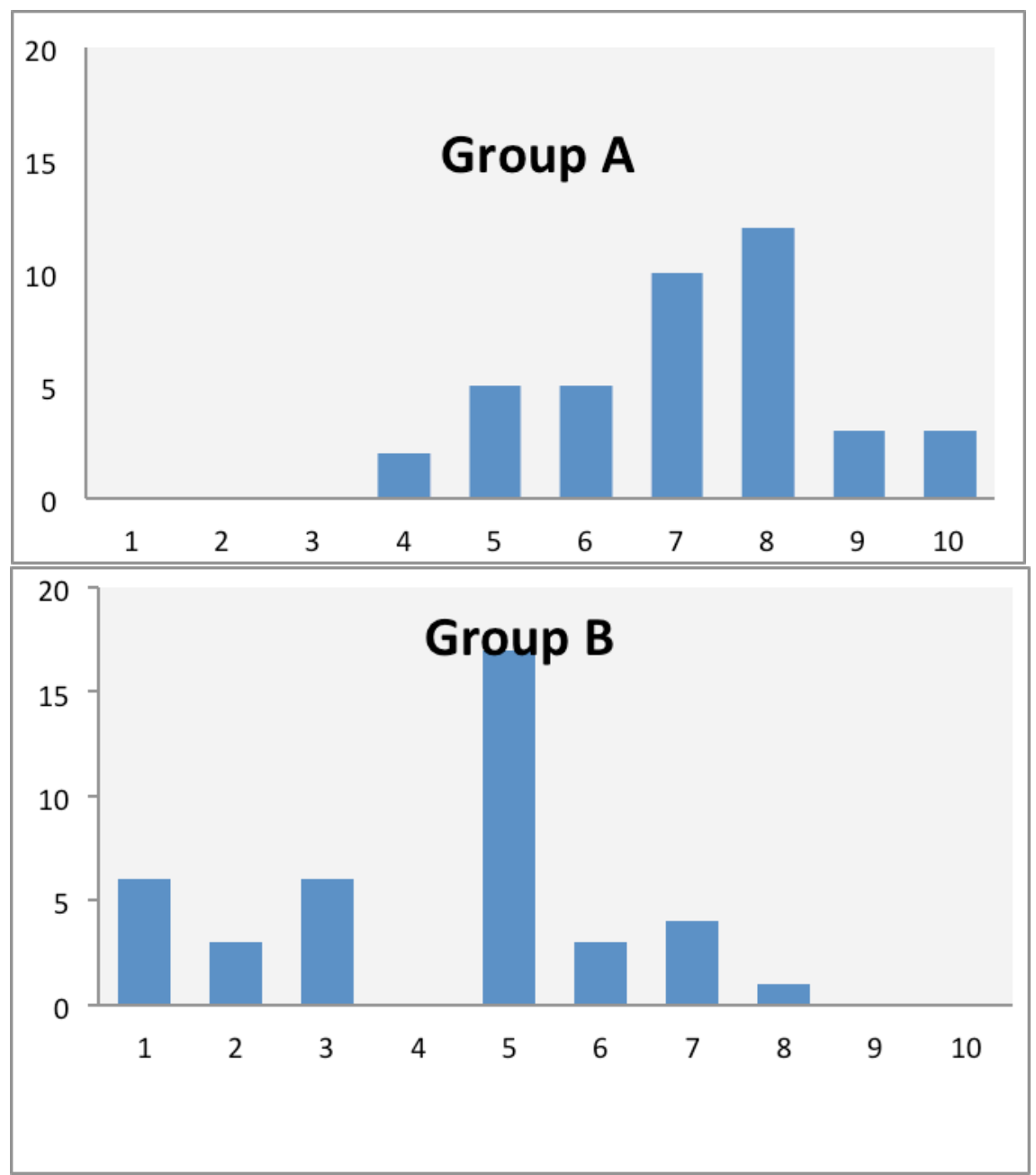

Table 3: Responses to question five by bar chart.

The broad conclusion from these figures is that Group A markedly wanted the car to sink while Group B tended more towards the 'not bothered' part of the continuum. The data may look rudimentary, but the results show a significant difference between the median scores in the two groups. Since the data was ordinal and the two groups independent, the results were calibrated using the non-parametric Mann-Whitney U test (see Appendix 2). The test statistic is 201 and $p<0.001$, so the null hypothesis (i.e. that there would be no difference between the groups) can be rejected at the $5 \%$ level. 
There is good statistical evidence therefore that the median score in Group A is significantly higher than in Group B.

Although circumspection is needed in the interpretation of an experiment like this, it is intriguing nonetheless that the removal of the KM is enough to prompt a marked change in both reactions to, and expectations of, the narrative denouement. Although Group B see Bates initially pushing the car and, at the end, delivering the self-satisfied leer, the micro-dynamics of the narrative delivery has been altered in this group's version in such a way as to engender a shift towards disinterest or indifference at the car's (and Marion's body's) progress. Without the strategic use of the eyeline-match and point-of-view cutting, subjectivity is de-intensified and with it the anchoring possibilities offered by the KM.

In contrast to this, the shot / reverse shot patterns in sequences 3 and 5 are the very features of narrative delivery which lock the group A participants into what the character (Bates) sees, and only what he sees. The context in the questionnaire makes clear that Bates is attempting to cover up the murder of an innocent woman. Moreover, two thirds of all the participants, across both groups, were able to identify the film and were fully aware therefore of Bates's psycho-delusional behaviour and his culpability in Marion's murder. Nonetheless, it was the A group who suspended this ethical framework in favour of identification with the preferred narrative outcome of the character. The effects, it seems, of the positioning of a particular kind of intradiegetic character within the story are sufficient to over-ride frameworks of expectation about what is just, decent or honourable. Our want to see that 'good will out' is superseded by our ultimately wanting the same as what the 'baddie' wants. 
One of the important factors behind the different reactions by the two groups may be in the contrast between narrative scene and narrative stretch. The former category, embodied by Hitchcock's original, allows viewers to share the information that a character learns at the same precise moment in the narrative. Moreover, in the initial 'straw poll' on the original clip (Simpson 2010: 308), when asked what made them side with the actions of so repugnant a character, a number of respondents replied that they felt manipulated because 'we see what he is thinking' (my emphasis). Interestingly, none of the informants purported to know what Bates was thinking, but the non-verbal clues perceived were a sufficiently solid platform on which to build an affective response. This line of reasoning seems to be borne out by the sort of commentary on Hitchcock's narrative style that can be found both on online blogs and on designated film websites. The idea of 'manipulation' is constantly at the fore and is typified by comments like: 'Hitchcock manipulates us into following whoever the protagonist of the moment happens to be' (film.com, 2013).

Furthermore, the present experimental study, perhaps more by accident than design, offers some intriguing qualitative material that could provide further interrogation of the interface between morality and narrative urgency. For example, two informants added to their numerical score a hand-written apology ('Sorry!') alongside a handdrawn 'sad face' icon: ' $\circ$ ' . Remarkably, one of these responses was from a group B participant who answered 1 to question 5, the other from a group A participant who answered 10 ! In a wonderfully conflicted opposition, the B participant appears to have sought the morally right outcome where the car remains visible, while reluctantly signalling that this runs counter to the character's preferred outcome. The A participant in wanting the car to sink is persuaded by the local 
mechanics of the ongoing narrative, but is nonetheless aware of the moral failure in doing so.

These results of course help underscore the evidence from experimental psychology surveyed earlier. That is to say, the urgency of the character's situation not only has an important bearing on how readers react to a story, but the completion of the action initiated, even if 'immoral', is easier to integrate psychologically. However, the experiment conducted here, and the foregoing development of the SP, $\mathrm{KM}$ and $\mathrm{BB}$, tries to locate such findings in a more full-blown model for the stylistic analysis of narrative. Moreover, the texts upon which the concepts are tested are not customised props designed by the researcher but are instead derived, if even in the first instance, from genuine works of both film and prose narrative. The following concluding section consolidates the model advanced thus far and suggests how it might be aligned with other parallel work in stylistics. It also considers a number of new directions in which the exploration of narrative urgency might be taken.

\section{Conclusion}

This article has adopted a mixed approach to narrative analysis and has, in truth, assembled somewhat of a smörgåsbord of stylistic methods. In its development of a framework for exploring narrative urgency, it has been partly inductive, partly empirical, partly orientated towards prose fiction and partly towards film narrative. In this respect, it might be tempting to try to draw together all of the components into a single formula which captures narrative urgency (NU) thus:

$$
\mathrm{NU}=(\mathrm{SP}+\mathrm{KM}) \div \mathrm{BB}
$$


The formula postulates that narrative urgency is a product of the combination of the Stylistic Profile and the presence of the Kuleshov Monitor, although this combination is attenuated by the perception of a Burlesque Block. Appealing in its simplicity it may be, but much more work needs to be done across both prose and film genres to ground the formula and to test it sufficiently. For example, the filmic reflexes of the SP, only marginally touched upon in the discussion of narrative scene above, need further investigation. Parallel to this, the KM's function in prose fiction is another area that requires scrutiny, although preliminary investigation of this has raised some interesting issues. In Graham Greene's novel Brighton Rock, the violent, sociopathic central figure of Pinkie / 'the Boy' makes for an interesting parallel with the Bates character in Psycho. At key moments of narrative urgency, Greene uses simple 'external' cuts to Pinkie: 'The Boy’s cheek twitched' (Greene 2011: 27); 'The Boy’s hands came out of his pickets, the knuckles clenched white.' (56) and so on. Without any discursive elaboration of what the Boy is feeling, the fear experienced by other characters is consolidated by directed 'point of view' shots towards him: ' . . a all three stared at the Boy in silence' (24).

These broader themes lead to other work in stylistics against which the present model needs to be evaluated and, where possible, aligned. Many cognate aspects of narrative style have been explored in stylistic research, including the portrayal in stories of fear, empathy, pace, peril, suspense, and of course, emotion. There is no doubt the model proposed here has numerous and significant interactions and overlaps with these other categories. For example, the development of empathy in stories is explored in cognitive-poetic terms across Stockwell (2009: 56-104), while Bousfield and McIntyre look specifically at how certain types of camera angles and over-the- 
shoulder shots help engender the emotion of fear in film narrative (Bousfield and McIntyre 2011). Toolan explores how readers are guided broadly in their experiences and expectations of narrative progression (2009, and this issue). He closes in on the idea of narrative suspense, suggesting that one of the narratological conditions for this trope is a 'fork' in the story where alternative outcomes are foreseen by the reader (2009: 167). (This framework alone would make for an interesting cross-analysis of the car in the swamp scene explored earlier). Another cognate narrative trope is pace and speed, addressed by Prince (this issue) and Stockwell with his model of 'action chaining' (Stockwell 2009). Stockwell offers an analysis of a 'rattling action sequence' from Tolkien's Lord of the Rings where the company of the ring are confronted by the Balrog (Stockwell 2009: 184-5). And again, a useful cross-analysis of the Tolkien scene could be undertaken using the narrative urgency framework developed in this article.

In terms of experimental design, a much greater range of textual material needs to be used to probe informants' reactions to different patterns in both film and prose narratives. A particular problem concerns the informant base used in experiments like this one, and, seemingly, in most experiments on narrative processing. Bluntly put, undergraduate students, especially students of English in well appointed universities, do not in any way represent the generic class of 'reader'. By the same token, structured reaction tests in de facto laboratory conditions in no way approximate the activity of 'reading'. It is wrong therefore to assume that the psycholinguistic data elicited under such conditions stands for all readers, as there are a host of other important cognitive, contextual and socio-pragmatic matrices through which individuals interact with texts. The next stage of the present project will therefore attempt to address this problem by rolling out the same 'car in the swamp' experiment 
to a larger constituency. Online resources such as 'Survey Monkey' (2013) offer access to very large informant bases, informants for whom the only known demographic is that they are prepared to be participants in an online survey.

This article has attempted to marry stylistics with experimental work which explores how readers and viewers process narrative texts. Undoubtedly, numerous other intersections between the two approaches can be drawn, alongside parallel explorations of other crossing points between narrative style and cognitive affect. The present study has sought to underscore the continued importance of stylistic analysis in research into narrative experience and understanding. After all, a change in stylistic patterning, even at the micro-level of textual organisation, can for readers have profound interpretative, affective, and even moral, implications.

\section{References}

Bousfield D and McIntyre D (2011) Emotion and empathy in Martin Scorsese's Goodfellas: A case study of the 'funny guy' scene. In: Piazza R, Bednarek M and Rossi F (eds.) Telecinematic Discourse: Approaches to the Language of Films and Television Series Amsterdam: John Benjamins, pp. 105-123.

Conrad, J. (2011) [1907] The Secret Agent Harmondsworth: Penguin Classics.

Egidi G and Gerrig R (2006) Readers' experiences of characters' goals and actions. Journal of Experimental Psychology: Learning, Memory and Cognition 32(6): 13221329.

Film.com (2013) What's the Big Deal?: Psycho (1960) http://www.film.com/movies/whats-the-big-deal-psycho-1960 (accessed 2 Feb 2013)

Fowler R (1986) Linguistic Criticism. First edition. Oxford: Oxford University Press.

Gavins J (2007) Text World Theory: An Introduction Edinburgh: Edinburgh University Press.

Genette G (1980) Narrative Discourse New York: Cornell University Press. 
Gerrig R (1993) Experiencing Narrative Worlds New Haven: Yale University Press.

Gerrig R and Rapp D (2004) Psychological processes underlying literary impact.

Poetics Today 25 (2): 265-281.

Gibbs R W Jr (1994) The Poetics of Mind: Figurative Thought, Language and Understanding Cambridge: Cambridge University Press.

Greene G (2011) [1938] Brighton Rock London: Vintage Books.

Halliday MAK and Matthiesson CMIM (2004) An Introduction to Functional Grammar Third edition. London: Edward Arnold.

Hitchcock A (2013) Hitchcock's pure cinema - the Kuleshov effect.

http://www.youtube.com/watch?v=TNVf1N34-io (accessed 22 January 2013)

Jerome JK (1986) [1889] Three Men in a Boat London: Everyman Classics.

Kennedy C (1982) Systemic grammar and its use in literary analysis. In: Carter R (ed.) Language and Literature London: Unwin Hyman, pp. 82-99.

Levaco R (1974) Eikhenbaum, inner speech and film stylistics. Screen 15 (4): 47-58.

McEwan I (2001) Atonement London: Vintage Books.

Nash W (1985) The Language of Humour Harlow: Longman.

Oatley K (2003) Writingandreading: The future of cognitive poetics. In: Steen G and Gavins J (eds) Cognitive Poetics in Practice London: Routledge, pp. 161-173.

Pramaggiore M and Wallis T (2005) Film: A Critical Introduction London: Lawrence King.

Prince G (1988) The disnarrated. Style 22: 1-8.

Rapp DN and Gerrig R (2006) Predilections for narrative outcomes: The impact of story contexts and reader preferences. Journal of Memory and Language 54: 54-67.

Ross M (2012) The 3-D aesthetic: Avatar and hyperhaptic visuality. Screen 53 (4): 381-397.

Russell M (2005) The Kuleshov effect and the death of the auteur. FORUM 'Origins and Originality' 1. http://www.forumjournal.org/site/issue/01 (accessed 2 Feb 2013)

Simpson P (2003) On the Discourse of Satire Amsterdam: John Benjamins.

Simpson P (2010) Point of view. In: McIntyre D and Busse B (eds.) Language and Style London: Palgrave, pp. 293-310.

Simpson P and Canning P (forthcoming) Action and event. In: Stockwell P and Whiteley S (eds.) The Cambridge Handbook of Stylistics Cambridge: Cambridge University Press. 
Simpson P and Hardy D (2008) American sentences: Terms, topics and techniques in stylistic analysis. In: Stoneley $\mathrm{P}$ and Weinstein C (eds) A Concise Companion to American Fiction, 1900-1950 Oxford: Blackwell, pp.113-131.

Stockwell P (2009) Texture Edinburgh: Edinburgh university Press.

'Survey Monkey' https://www.surveymonkey.com/mp/take-a-tour/ (accessed $12^{\text {th }}$ September 2013)

Toolan M (2009) Narrative Progression in the Short Story: A Corpus Stylistic Approach Amsterdam: John Benjamins.

Werth P (1999) Text Worlds: Representing Conceptual Space in Discourse. Harlow: Longman.

Willemen P (1981) Cinematic discourse: The problem of inner speech. Screen 22 (3): 63-93. 


\title{
APPENDIX 1: THE QUESTIONNAIRE
}

\section{Introduction.}

The short film clip you are about to see involves a man attempting to submerge a car in a swamp. In the boot of the car, is the body of a woman - and we know at this point in the film that the woman has been murdered. The man is therefore attempting to destroy the evidence of the murder. After watching the clip through once, please answer the five questions below. Put your answers in the spaces provided

\section{Instructions.}

(i) From what film is this extract taken?

Answer:

(ii) What is the name of the actor in this scene? Please underline the correct answer.

\author{
Anthony Hopkins \\ Anthony Perkins \\ Carl Perkins
}

(iii) In which decade do you think this film was made?

Answer:

(iv) What is the number plate of the car?

Answer:

(v) On a scale of 1-10, how much did you want the car to sink? A score of 1 means you didn't want it to sink while a score of 10 means you wanted it to sink a lot. A score of 5 means you are not bothered one way or the other.

Write your score here: 
The Mann-Whitney $\mathbf{U}$ test is a non-parametric test for comparing two independent samples when data are on an ordinal (ranked) scale. It tests for equality of medians in the populations.

The hypotheses in this test are:

$\mathrm{H}_{0}$ : median score of group $\mathrm{A}=$ median score group $\mathrm{B}$

$\mathrm{H}_{1}$ : median score of group $\mathrm{A} \neq$ median score group $\mathrm{B}$ (i.e. the outcome anticipated in the experiment)

Data were analysed using Mann-Whitney $U$ test and the statistical analyses were performed with SPSS (SPSS 19.0 for Windows, SPSS Inc., Chicago, Illinois, USA).

Output from SPSS is as follows:

Ranks

\begin{tabular}{|c|c|c|c|c|}
\hline & $1=\mathrm{A}, 2=\mathrm{B}$ & $\mathrm{N}$ & Mean Rank & Sum of Ranks \\
\hline \multirow[t]{3}{*}{ Score } & 1 & 40 & 55.48 & 2219.00 \\
\hline & 2 & 40 & 25.53 & 1021.00 \\
\hline & Total & 80 & & \\
\hline
\end{tabular}

Test Statistics ${ }^{\mathrm{a}}$

\begin{tabular}{|l|r|}
\hline & \multicolumn{1}{|c|}{ Score } \\
\hline Mann-Whitney U & 201.000 \\
Wilcoxon W & 1021.000 \\
Z & -5.859 \\
Asymp. Sig. (2-tailed) & .000 \\
Exact Sig. (2-tailed) & .000 \\
Exact Sig. (1-tailed) & .000 \\
Point Probability & .000 \\
\hline
\end{tabular}

a. Grouping Variable: $1=\mathrm{A}, 2=\mathrm{B}$

Interpretation

The sample median score in Group A was 7 and the sample median score in Group B was 5. 
The test statistic is 201 and $p<0.001$. The null hypothesis $\left(\mathrm{H}_{0}\right)$ is therefore rejected at the $5 \%$ level. There is evidence that the median score in Group A is significantly higher than in Group B. 